\title{
O CORPO DAS MASSAS NA ERA DA REPRODUTIBILIDADE TÉCNICA
}

\author{
Marlon Miguel* \\ marlonmiguel@gmail.com
}

RESUMO O problema das massas é uma questão moderna crucial e Walter Benjamin não cessou de abordá-lo. O fenômeno das massas surge com as grandes metrópoles e segue uma dinâmica concentracionária inteiramente nova. Além disso, a questão das massas é também correlata da relação a si que as técnicas modernas na era da reprodutibilidade técnica permitem. É o que ressalta Benjamin no fim de seu texto "A obra de arte na era da reprodutibilidade técnica" a partir da questão da propaganda. A imagem filmada estrutura de modo inédito a percepção das massas que podem, pela primeira, vez se apreender como um todo em seus movimentos, gestos e comportamentos. A massa se torna um "material" a ser "trabalhado", a ser "reproduzido", segundo a visão fascista, ou a ser "transformado", segundo a visão revolucionária. Este artigo propõe investigar os conceitos benjaminianos desenvolvidos nos anos 1930 para se pensar a arte tendo em vista esse plano de fundo histórico determinante para as suas teorizações.

Palavras-chave Benjamin, arte, reprodução, massa, aura.

ABSTRACT The problem of the masses is a crucial modern question, which was constantly approached by Walter Benjamin. The phenomenon of the masses emerges with the big cities and follows radical new concentrationary dynamics. Further, the advent of modern techniques of mechanical reproduction

* $\square$ Doutor em Filosofia Univ. Fed. do Rio de Janeiro, RJ/RJ - Brasil e em artes plásticas Univ. Paris 8 Vincennes Saint-Denis. Pesquisador no Laboratório Arts des Images et Art Contemporain (AIAC), Université Paris 8, Vincennes Saint-Denis/Paris - France. Artigo submetido em 31/08/17. Aceito em 08/10/17. 
enables a new relationship of the masses to themselves. Benjamin underlines this issue through the question of the propaganda in his text "The Work of Art in the Age of Mechanical Reproduction". The filmed image structures the perception of the masses that can, for the first time, apprehend themselves as a whole in their movements, gestures and behaviors. The masses become "material" to be worked on - to be "reproduced", according to the fascist point of view, or to be "transformed", according to the revolutionary point of view. This paper proposes to investigate the Benjaminian concepts developed during the 1930s to reflect on art while taking into account the historical background determining his theorizations.

Keywords Benjamin, art, reproduction, mass, aura.

\begin{abstract}
Nosso objetivo era a conquista da rua, - pelas ruas queríamos ganhar as massas. "A conquista das massas. Todo meio servindo a esse objetivo é bom". ${ }^{1}$ Seria então possível constituir uma linguagem política na qual o fim absoluto da ação é a conquista de uma massa que se trata em seguida, explicitamente, de levar ao estado de material? Mas isso, com uma condição: que os dois enunciados não sejam nunca conectados. E que o primeiro se articule com cadeias discursivas onde se exprime a apologia da tradicional e conservadora autoridade e da hierarquia; enquanto que a segunda derive das cadeias nas quais são exaltados os "movimentos revolucionários" e "o caráter revolucionário do Movimento". E o essencial se encontra sem dúvida aí: a perda de contato entre essas duas esferas do sentido, e é deslocando-a para assim controlá-la que o hitlerismo garante, mas de modo quase sonâmbulo e quase em sonho, a via de passagem.
\end{abstract}

Jean Pierre Faye, "Les langages totalitaires"

\title{
Introdução
}

O texto "Obra de arte na era da sua reprodutibilidade técnica", de Walter Benjamin, termina se debruçando sobre a questão de como, com o advento das técnicas modernas, nasce uma relação inédita às massas. Analisando a propaganda, o filósofo alemão sublinha não tanto o conteúdo das imagens, mas antes a relação a si que a imagem constrói. A imagem filmada estrutura de um modo inteiramente novo a percepção das massas - esta pode, ela mesma, se observar; ainda mais, pela primeira vez na história, a massa é apreendida como

1 Referência ao texto "Combate por Berlim", de Joseph Goebbels: "A propaganda [...] só tem um objetivo; e certamente, na política, esse objetivo se chama sempre: a conquista das massas (Eroberung der Masse). Todo meio servindo a esse objetivo é bom" (Goebbels, 1934, p. 6). 
um todo em seus gestos, atitudes e movimentos. Por isso, "a massa é uma matriz da qual renascem atualmente todos os modos de se relacionar com a obra de arte" (Benjamin, GS1, p. 503) e "os movimentos de massa, e assim também a guerra, apresentam uma forma de comportamento humano que corresponde particularmente ao aparelho" (Benjamin, GS1, p. 506). A massa é dessa forma uma questão moderna incontornável, o "material" por excelência a ser trabalhado.

O problema da arte concerne também o problema das massas - tanto do ponto de vista do mercado e da produção de massa, quanto da própria estruturação do movimento de massa enquanto tal. Tanto o fascismo quanto o capitalismo se aproveitam dessa nova relação a si que o sujeito constrói através da imagem técnica. O sujeito pode, como nunca, se identificar ao objetoimagem "massa" que ele possui diante de seus olhos. O fascismo, em particular, explora ideologicamente essa possibilidade, buscando obter uma reprodução das massas segundo o modelo que lhe convém. Todavia, essa mesma técnica poderia servir a outros fins: a imagem cinematográfica poderia servir, avança Benjamin, à transformação das massas. É por isso que, em sua reflexão sobre a relação intrínseca entre arte e política, a questão da técnica é tão importante para Benjamin.

Três séries de textos seus, em particular, são determinantes para o desenvolvimento desses problemas: "Pequena história da fotografia" (fim de 1931), "O autor como produtor" (1934) e "Obra de arte na época da sua reprodutibilidade técnica" (diversas versões, 1935-1939). Cada um deles privilegia, em sua análise, uma prática artística distinta - a fotografia, o teatro épico de Brecht, o cinema -, mas tem em comum o mesmo princípio: a necessidade de reler toda a história da arte em função do desenvolvimento das técnicas de reprodução. Além disso, o contexto histórico, a ascensão nazista na Alemanha, é crucial para as análises do filósofo sobre a arte e veremos como a discussão estética é vista por ele como um campo de batalha determinante - a definição do estatuto da arte é um espaço privilegiado de confrontação política e ideológica.

Benjamin, sendo um judeu marxista, se vê diretamente implicado por esse contexto e se revela um crítico extremamente atentivo a esse campo. Por isso, toma posições radicais contra o fascismo, evidentemente, mas também contra certo "esquerdismo" (a intelligentsia da esquerda burguesa). Para se compreender a posição crítica benjaminiana, é preciso considerar esse campo de batalha enquanto uma luta pela ocupação de certos territórios semânticos: trata-se de interferir, de capturá-los, por vezes de retomar, por vezes de destruir certos conceitos, noções, palavras, expressões que circulam no campo discursivo. A 
batalha é também pela definição e pela utilização de significantes e enunciados que fundam a própria política.

Nessa conjuntura, Benjamin conduz uma luta contra a arte pura, autônoma, cultual, mágica, em suma, aurática, traduzida em última instância pelo slogan de l'art pour l'art e cuja máxima realização seria o próprio fascismo. Para Benjamin, não existe algo como uma arte autônoma, ou "autêntica", senão enquanto ideologia. Nesse sentido, a imbricação entre arte e política é total.

Enfim, um último aspecto essencial a ser levado em consideração é o fundo marxista das análises benjaminianas desse período. O que caracteriza os objetos a partir do século XIX é o seu estatuto de mercadorias. Marx mostrara como o fetichismo camufla a produção e o trabalho, de modo que não restaria senão a abstração das mercadorias. Por essa razão, Benjamin sublinha tanto a importância do aprendizado da técnica: esta não deve escapar aos seus utilizadores, ou ainda os utilizadores não devem se alienar nos aparelhos. A técnica moderna na era da reprodutibilidade técnica é dialetizada por Benjamin, possuindo assim duas faces: por um lado, pode ser liberadora e extremamente democratizante; por outro, pode servir a uma nova forma de culto ainda mais perigosa do que a arte tradicional. Essa dialética imóvel, sem resolução definitiva, sublinha a tensão do conceito de técnica, mas a transfere para a questão dos usos da técnica, para a análise (crítica) de práticas bem antes de conceitos gerais de Arte.

\section{Os impasses da intelligentsia esquerdista: o desprezo das massas}

A conferência pronunciada por Benjamin em 1934, no Instituto para o Estudo do Fascismo, em Paris, intitulada "O autor como produtor", é talvez o melhor texto escrito pelo filósofo para compreendermos sua posição estético-política. O texto se abre com o debate em torno da noção de tendência, problematizada a partir da perspectiva do posicionamento do escritor no seu processo de escrita, ou seja, da sua "liberdade" ou da sua "autonomia". O escritor deveria tomar posições e orientar sua escrita - em nome da consciência de classe, por exemplo - ou guardar sua inquestionável liberdade? Para Benjamin, "tendência" é a "palavra-chave" (Benjamin, GS2, p. 684) que funda a doxa contemporânea burguesa e conduz de maneira intelectualmente desinteressante o debate, visto que ela é marcada por um dualismo: por um lado, exige-se a justa tendência do artista; por outro, espera-se uma obra de alta qualidade. Benjamin propõe deslocar o problema ao mesmo tempo que o dialetiza: em uma verdadeira obra poética, a tendência é politicamente justa se também é literariamente justa, ou seja, qualidade poética e dimensão política se coimplicam mutuamente, 
há um acordo - stimmen, como se diria de afinar um instrumento ${ }^{2}$ - entre ambas. Benjamin pensa aqui no conceito de forma e possui como paradigma as vanguardas artísticas - em particular as russas - que avançam proposições políticas revolucionárias porque avançam tendências artísticas traduzidas em novas técnicas. Ouve-se ao fundo o famoso lema de Maiakovski: "Sem forma revolucionária não há arte revolucionária", no qual há recusa de toda idolatria pura e simples baseada apenas no conteúdo ou apenas na forma.

Em vez de pensar a arte a partir dos conceitos de "tendência" e de "autonomia", de "forma" e de "conteúdo", Benjamin propõe pensar a partir da questão das "relações de produção": como uma obra se situa nessas relações e não em face delas? Deslocamento essencial permitindo que a questão seja colocada em termos materialistas a partir do conceito de "técnica". A tendência de uma obra poética, por exemplo, passa assim a ser avaliada em termos de progresso ou de regresso da técnica literária.

É preciso notar que a "técnica" não é de forma alguma um advento moderno, mas, desde que o homem é homem, sempre houve técnica. ${ }^{3}$ A técnica é o modo pelo qual o homem se relaciona com a natureza, com o meio e o modo através do qual ele a controla. Nesse sentido, as danças "primitivas" também consistem em meio técnicos para controlar a natureza - certamente em um sentido "mágico", podendo ser localizadas também no que Benjamin (1993, p. 148) chama de "primeira técnica". Mas, como aponta o filósofo, a técnica é sempre histórica e se transforma ao longo do processo de hominização do homem. Desse modo, a maneira segundo a qual o humano se produz e se fabrica é intimamente correlata dos desenvolvimentos técnicos. Ressaltar que a técnica é histórica serve a Benjamin para sublinhar que as formas de produção também se transformam. Assim, o romance é, por exemplo, uma maneira atual de se fazer literatura, o que não foi sempre o caso e não há nenhum motivo para que essa forma perdure para sempre.

$\mathrm{O}$ argumento central de Benjamin pode ser facilmente resumido assim: enquanto não pensarmos na relação entre autor e produtor, não avançaremos esteticamente e politicamente no debate. É preciso, pois, pensar na posição ocupada pelo autor na produção: trata-se de uma posição exclusiva e separada

2 "Zeigen mochte ich Ihnen, daß die Tendenz einer Dichtung politisch nur stimmen kann, wenn sie auch literarisch stimmt" (Benjamin, GS2, p. 684).

3 A esse sujeito, ver a obra essencial Le geste et la parole, do paleontólogo francês André Leroi-Gourhan, que demostrou a relação intrínseca entre linguagem e técnica. A verticalidade liberando a mão da locomoção permitiu uma atividade técnica inteiramente nova em relação ao macaco, permitindo ao homem desenvolver sua atividade técnica em órgãos não orgânicos, ou seja, nas ferramentas. Ver também a obra de Marcel Mauss, em particular "Les techniques du corps", e os textos de Benjamin "Sobre a faculdade mimética" e "Doutrina das semelhanças" (Benjamin, GS2, 210-213; pp. 204-210). 
dos demais? Essa posição supõe, uma vez mais, novas hierarquias, novos autoritarismos? Por isso, ainda, a posição do expert, do especialista, deve ser questionada enquanto pressupõe essas diferenciações - enquanto pressupõe uma "desigualdade de inteligências" (Rancière, 2004, 2017). Ao longo de seus textos, Benjamin buscará justamente autores que servem de exemplo de tentativas de se pensar técnicas inovadoras, novas formas de produção coletiva. Para Benjamin, o artista revolucionário por excelência é o "operativo" (Benjamin, GS2, p. 696), aquele que transmite a técnica a outros e permite ativamente a expansão da produção artística, pois a transformação se inicia precisamente com a tentativa de destruição da oposição entre aquele que produz e aquele que contempla. O produtor deve ensinar aos demais a igualmente produzir, o artista transforma aqueles a quem fala em coartistas. É o caso de Sergei Tretyakov, participante do círculo dos formalistas russos e expoente de um jornalismo de vanguarda praticado no início da União Soviética. Tretyakov, em 1928, no momento da coletivização das terras e da palavra de ordem "escritores aos colcoses!", organiza no campo salas de leituras, jornais colcoses, rádios e cinema itinerantes etc. Ao contrário do jornalismo ocidental e burguês, esse tipo de iniciativa poderia propiciar um jornal como meio de expressão comum baseado em uma formação "politécnica” (Benjamin, GS2, p. 688), graças ao qual se assistiria ao apagamento da diferença entre autor e leitor e ao fim da ideia segundo a qual apenas especialistas podem escrever. Com efeito, logo após a revolução soviética, houve a explosão de iniciativas artísticas que visavam à coletivização dos meios de produção da arte. Outro exemplo relevante seria sem dúvida o cine-trem do diretor Aleksandr Medvedkin, cuja trajetória foi tão bem retratada por Chris Marker em Elegia a Alexandre (1993). O projeto consistia em um trem contendo em seus vagões câmeras, estúdios de montagem, equipamentos de som que percorreria a União Soviética e pararia em vilarejos onde faria ateliês de filmagem com os habitantes locais.

A técnica que interessa a Benjamin, a técnica revolucionária, é aquela capaz de pensar a democratização, a coletivização e a horizontalização dos processos criativos. Não se trata assim de uma transformação das consciências, das ideias, do Geist, mas uma transformação material das condições de produção. Segundo Benjamin, a intelligentsia esquerdista alemã, a esquerda burguesa, se viu forçada, por conta dos extremismos, a adotar convicções revolucionárias, sem, no entanto, engajar posições concretamente revolucionárias. É essa contradição que está no coração da crítica da conferência de 1934.

Benjamin ataca dois movimentos estéticos contemporâneos seus para exemplificar e identificar sua crítica: o Ativismo (Aktivismus) e a Nova Objetividade (neue Sachlichkeit). O primeiro movimento, liderado por nomes como Kurt Hiller e Heinrich Mann, avança, como aponta Benjamin, o slogan da 
"Logocracia". Na definição de Hiller, o Ativismo seria um "socialismo religioso" capaz de criar uma nova dimensão propriamente popular (Volkstümlichkeit) ou, para o poeta expressionista Ludwig Rubiner, de criar uma "massa santa" (vide Rothe, 1969). O Ativismo, defendendo o princípio do pacifismo, propunha a substituição do termo de "intelectual" (Intellektueller) pelo de Geistiger, e a liderança espiritual do povo por esses intelectuais "dotados de espírito". Contra a figura do homem político ou do chefe de partido, ${ }^{4} \mathrm{o}$ intelectual seria a figura dotada do "bom senso", capaz de pensar melhor e portanto de melhor defender os interesses das massas. Benjamin sublinha a posição extremamente "reacionária do princípio dessa imagem do coletivo" (Benjamin, GS2, p. 690), segundo a qual o intelectual é hipostasiado como figura à parte e a massa é tomada como incapaz de pensar por si própria. A questão do culto, central no texto sobre a "Obra de arte", aparece, pois, já aqui, e Benjamin antecipa o perigo do culto do líder espiritual, que estaria, segundo ele, tão presente na esquerda burguesa e daria assim livre passagem para o fascismo, e cujo pressuposto é um verdadeiro "desprezo das massas" (Sloterdijk, 2002). Para Döblin, por exemplo, em "O que fazer?", invocando ideais abstratos como "humanidade", "liberdade" e "tolerância", o intelectual deveria se posicionar ao lado do proletariado na luta de classes a partir de suas opiniões, convicções e disposições. Tal posição, avança Benjamin, extremamente pobre e insuficiente, se reduziria a de um "mecenas ideológico" (Benjamin, GS2, p. 691). Ao contrário, é preciso pensar a posição do intelectual e do artista dentro do processo de produção. ${ }^{5}$

Seguindo o conceito de Brecht de Umfunktionierung - algo como a transformação de função ou "refuncionalização" -, Benjamin propõe pensar de outro modo a questão. O intelectual não deve alimentar as formas de produção, mas trabalhar ativamente de modo a transformá-las no sentido do socialismo - isto é, no sentido da coletivização da produção segundo o postulado de uma igualdade radical das inteligências. Para Benjamin, o intelectual ou o artista pode até tomar posições que possuam a (falsa) aparência de princípios de esquerda, mas a simples convicção não contribui para o combate se ela retoma precisamente os mesmos modos de produção elitistas do fascismo ou do capitalismo. Com efeito, a Alemanha dos anos 1920 mostrou de forma exemplar como o aparelho de produção e de publicação burgueses podiam capturar, "assimilar e mesmo propagar” (Benjamin, GS2. p. 692) temas revolucionários, sem, no entanto, nada

4 Benjamin se posiciona claramente contra abstração e a ilusão do homem apolítico, do "homem natural" (fora da política), mobilizando Marx em seu texto sobre Karl Kraus (Benjamin, GS 2, p. 364).

5 Ver também a carta a Alfred Cohn de 4 de julho de 1936, onde Benjamin afirma que esses intelectuais se sentiriam como que "ameaçados em suas atividades de homens letrados que parece funcionar tão bem" (Benjamin, 1978, p. 716). 
mudar estruturalmente. Uma transformação estrutural significaria democratizar a produção em vez de deixá-la nas mãos de alguns poucos.

A arte que interessa a Benjamin deveria, através de sua técnica, pôr em questão a estrutura da organização social em vez de justamente reificá-la. É o que fizera, segundo o filósofo, o dadaísmo, por exemplo, ao questionar a ideia de autenticidade da arte criando composições de naturezas mortas com objetos ordinários tais que dinheiro ou guimbas de cigarro. Esses procedimentos foram em seguida incorporados à montagem fotográfica. Esta, porém, se tornou cada vez mais complexa e começou a ser novamente utilizada como um novo modo de reificar o real. Benjamin ataca aqui a Nova Objetividade e, em particular, o trabalho fotográfico de Renger-Patzsch (Die Welt ist schön/O mundo é belo, 1928). A estetização da fotografia permite que mesmo a miséria ou o combate a ela se tornem objetos de fruição, de consumo e de prazer. Tudo pode, como diz Kurt Eisler, se transformar em "mercadoria enlatada" (Benjamin, GS2, p. 694). O “valor mágico” (Benjamin, GS2, p. 371) que a técnica fotográfica permite é essa estetização mortífera que renova e reifica o mundo tal como ele é, revestindo-o de novos contornos, colorindo-o, repondo-o na moda e impedindo assim sua transformação.

\section{Os perigos da fotografia: estetização, identificação e fascinação}

Esses problemas já haviam sido longamente desenvolvidos alguns anos antes na célebre "Pequena história da fotografia". A análise de Benjamin trabalha a partir de uma tensão dialética. Por um lado, o advento da fotografia permitiria dessacralizar a arte, acabar com a ideia da autenticidade e do original. Por outro, ela reinstauraria um valor mágico, uma aura, como se as coisas se presentificassem mais do que nunca na imagem fotográfica, ao mesmo tempo que permanecem inacessíveis - e tanto mais inacessíveis quanto mais visíveis se tornam graças à difusão possibilitada pela reprodutibilidade técnica: a imagem de uma estrela de cinema poderá ser facilmente vista em inumeráveis revistas. A foto torna assim os objetos ao mesmo tempo próximos e longínquos, e, na realidade, quanto mais ela mostra, mais ela esconde. Tal é a aura que a fotografia e em seguida o cinema poderão criar como nunca antes fora possível com outras formas artísticas. Há dessa forma com a fotografia uma dialética na imagem entre o real (a foto, a coisa fotografada) e o imaginário (minha representação da foto), há um descolamento entre o nome e a coisa.

O valor mágico da fotografia reside precisamente nesse descolamento, nessa dialética entre o próximo e o longínquo capaz de causar um fascínio incontrolável naquele que a contempla. E é justamente essa dimensão fascinante, 
de identificação com a imagem, que Benjamin procura criticar em seu texto. Sua posição é, desse modo, diametralmente oposta a de um Barthes (A câmara clara), por exemplo, que avança uma posição justamente completamente fascinada. Barthes se interessa pelo ça a été da foto, o punctum que toca aquele que a olha e que faz com que ele retorne ao ponto original: "o punctum é uma espécie de fora de campo sutil como se a imagem lançasse o desejo para além do que ela dá a ver" (Barthes, 1980, p. 93). Em A câmara clara, trata-se da fotografia da mãe do autor, que morta, longínqua e inatingível, se representifica incessantemente na imagem. Se Barthes faz sua análise do ponto de vista do imaginário, isto é, de como o sujeito, identificado à imagem, se representa essa imagem, e se vê como que ao mesmo tempo colado a ela e para além dela, Benjamin segue outra via. Na "Pequena história da fotografia", o filósofo alemão vai sublinhar que, apesar da técnica do fotógrafo, da atitude do modelo, de toda a vontade de perfeição e de mise-en-scène para a representação de algo, o que interessa é antes aquilo que escapa. Também ressaltando o punctum, Benjamin enfatiza, no entanto, a forma como o real (Wirklichkeit) "atravessa queimando" (durchsengen) a fotografia, ou seja, esburacando-a (Benjamin, GS2, p. 371). O real é uma "minúscula faísca do acaso" (winzige Fünkmen Zufall), aquilo que se introduz acidentalmente apesar do fotógrafo e da sua vontade de representação. Nessa falha, nessa brecha aberta, se introduz assim esse índice do real, espaço aberto, imperceptível e inominável. ${ }^{6}$ Diferente de Barthes, a fotografia não é, portanto, subsumível ao símbolo, mas é, para Benjamin, o traço-índice que esburaca a foto. Para o primeiro, a identificação com a imagem interdita toda distância necessária para justamente poder observá-la e criticá-la - o desejo do observador é jogado para além do que ela dá a ver -; para o segundo, ao contrário, esse buraco causa um estranhamento, presentifica e ativa o observador fixando o seu olhar na imagem, interpelando a crítica - a fotografia dá a ver algo.

A primeira dimensão positiva da fotografia evocada por Benjamin diz respeito então à potência da fotografia de dar a ver - não tanto de desvelar, mas de dar a ver o véu, isto é, as condições materiais nas quais a foto foi feita. ${ }^{7} \mathrm{Em}$ outras palavras, a fotografia poderia servir a nos ensinar a ver de outra maneira, em particular, por estarmos com a vista tão habituada e por isso incapazes de ver; ela poderia interromper o automatismo visual, ensinando-nos sobre nosso

6 O inominável não é o inefável, mas aquilo que sendo real está para além (ou para aquém) da significação simbólica. O real resiste à significação, o que não significa que ele não possa ser constantemente ressignificado, mas sim que essa significação possui sempre algo de arbitrário e não esgota o seu sentido.

7 A questão do véu - e não a do "desvelamento" - é presente em Benjamin desde seu trabalho sobre As afinidades eletivas, de Goethe. Não interessa o que há por detrás do véu (perspectiva da representação), mas sim o próprio véu (Cf. Benjamin, GS1, p. 195). 
inconsciente visual - e isso através dos procedimentos técnicos possíveis na montagem. A fotografia, enquanto ferramenta científica, ensina-nos sobre nossos corpos, gestos, maneiras de se movimentar, de se comportar. Mas a fotografia serviria também para dar a ver o mundo "infinitamente pequeno" que não vemos a olho nu e que, no entanto, habita nosso inconsciente. Por isso, a fotografia poderia ajudar a ler o real, arrancando nossa visão da magia, ajudando a enxergar através da névoa que encobre uma época: o aparelho se introduz profundamente no real para nele intervir (Benjamin, GS1, p. 495). Não se trata nunca de representar o real, de dá-lo em sua totalidade, mas de construílo na montagem. Em outras palavras, ler o real significa, para Benjamin, já tomar uma posição em face da realidade, fabricando-a em sua apresentação (Darstellung). Enfim, a fotografia "absorve a aura do real como faria com a água de um navio submerso" (Benjamin, GS2, p. 376). Benjamin se refere aqui ao trabalho de Eugène Atget, que teria conseguido dar a ver espaços cotidianos de Paris tornando-os estrangeiros.

Benjamin faz de Atget o primeiro grande fotógrafo e precursor do surrealismo. Diferentemente do uso comercial da fotografia que não faz senão maquiar a cidade - como é o caso de cartões-postais, por exemplo, cujo objetivo é reproduzir uma beleza fascinante de modo que se tenha vontade de visitar a cidade fotografada -, Atget, segundo Benjamin, teria sido capaz de absorver a aura dos espaços urbanos, tornando-os estranhos, estrangeiros. A potência de pontuação que Benjamin reconhece nas fotografias de espaços cotidianos - e não dos grandes símbolos da cidade - feitas por Atget diz respeito ao poder de tornar estranho/estrangeiro que ele consegue obter ao fotografar esses espaços esvaziados, sem ambiente, clima, atmosfera (stimmungslos). Não se trata assim do reconhecimento do real - e por consequência de sua reificação -, mas de expor, de pôr a nu a "bizarrice" dos espaços e dos "véus" através dos quais nos habituamos a observar o mundo. Benjamin revela, com Atget, que há toda uma política do olho, e que se trata não de exaltar o real, mas de expor seus detalhes obscuros. Há algo da mesma natureza em Jacques Tati, que soube, com muito humor, em Playtime, por exemplo, dar a ver a "bizarrice" da cidade e do turismo moderno. Não vemos no filme senão essa cidade "genérica", cujos monumentos de Paris aparecem somente refletidos nas fachadas espelhadas de grandes edifícios. Essa cidade, que como em uma metacena do filme em uma agência de viagem mostra bem, poderia ser a Cidade do México, São Paulo ou Nova York. Pouco importa, para o turista que as visita, são todas iguais.

A fotografia, como é o caso de toda técnica, se encontra entre um uso desmistificador - é a fotografia que assume seu papel construtivo, de fabricação, onde para se ler o real é preciso construí-lo, montá-lo: não há apreensão sem 
construção - e um uso mistificador - é a fotografia "criadora", reenviando ao fantasma e ao fetiche da personalidade criadora; é a fotografia tanto da estetização quanto da objetividade neutra, ambas às vezes se confundindo.

Die Welt ist schön é para Benjamin o exemplo perfeito dessa exaltação despolitizada do mundo. Mesmo as usinas Krupp - aquelas mesmas que apoiariam alguns anos mais tarde abertamente o nazismo e participariam ativamente de suas políticas de guerra e de genocídio ${ }^{8}$ - aparecem belas nas fotografias do livro. Essa estetização, causando uma identificação do observador, tem como único efeito a reificação, a aceitação. A aura é precisamente o efeito dessa estetização e que impede o sujeito de abordar o objeto, restando-lhe apenas a possibilidade de estabelecer com o objeto uma relação de ritual, de culto, de contemplação.

Um fotógrafo como Sebastião Salgado exemplifica bem a crítica benjaminiana. Suas fotografias, extremamente estetizantes, produzem no observador uma identificação em vez de uma relação crítica - um elemento marcante de sua prática é a maneira como em seus retratos há toda uma miseen-scène na qual as pessoas fotografadas, seus "modelos", sempre olham para a câmera. Além disso, Salgado nunca põe em questão sua própria posição nas situações grotescas onde se encontra (a fome, a guerra), permanecendo precisamente ao lado, fora/em face das situações, enquanto um observador externo, ao mesmo tempo que se autorreconhece como uma espécie de "salvador" simplesmente por retratar tais situações. Suas fotografias, mais próximas de um fotojornalismo, não fazem senão no máximo informar sobre fatos sem tomar uma posição real em face deles.

No recente $O$ sal da terra (2014), Wim Wenders e Juliano Ribeiro Salgado caem na mesma armadilha ao tratar do trabalho do fotógrafo. A montagem do filme, valendo-se de um pathos extremamente exagerado, visa forçar uma emoção no espectador e uma identificação com as fotos de Salgado. Os diretores seguem o percurso do fotógrafo até suas últimas imagens compiladas no livro Gênesis (2013). Esse livro, cujo objetivo, nas palavras do fotógrafo, seria mostrar a beleza da natureza virgem da Terra intocada pelo homem, marcaria uma descontinuidade: pela primeira vez, Salgado deixaria de fazer fotos "sociais" para fazer uma fotografia de paisagem. Todavia, é sintomática a semelhança entre as fotos "sociais" e as de "paisagem". Ambas são frequentemente encobertas por uma espécie de névoa, evocando certo feitiço e mistério, certa magia fascinante. São belas fotografias, independentemente do contexto em que são feitas, como se permanecessem encarceradas lá onde foram feitas, mas à

8 Krupp teve mesmo uma usina chamada Bertha em Auschwitz, onde usou centenas de prisioneiros do campo para trabalho forçado. 
parte, e como se pertencessem a um outro mundo longínquo que não guarda relação alguma com o mundo daquele que as observará na galeria de Salgado no Marais, em Paris. Esse efeito de "longínquo" presente na estética dessas fotografias se agrava ainda mais por não serem acompanhadas por nenhum tipo de contextualização ou de crítica por detrás das fotos que permitissem dar a ver a maquinaria que estrutura essas guerras, êxodos, fomes. Resta o puro espetáculo da miséria em retratos onde não vemos nunca humanos, mas antes coisas absorvidas nas imagens. ${ }^{9} \mathrm{O}$ discurso abstrato e universalista de Salgado em $O$ sal da terra coroa o espetáculo: o homem é um ser cruel, um animal terrível, o humano não merece essa terra. Mensagens passivas de reificação de um mundo que correspondem perfeitamente às imagens acríticas, pois se tratam de fotos "mágicas" no sentido mais negativo da palavra em que o espectador é forçado a uma identificação, incapaz de enxergar para além da névoa enfeitiçante. Todas as fotos são similares, homogeneizadas, onde no fim retratos ou paisagens são a mesma coisa. $\mathrm{O}$ filme acentua ainda mais esse efeito vendendo a imagem de um homem preocupado com outros homens, um "homem humano em um planeta inumano", um homem que "fugiu" da ditadura militar brasileira - quando apenas deixara o país com sua mulher -, que "abandonou" a profissão fácil de economista - quando tinha recursos suficientes para que isso fosse antes um cálculo do que um verdadeiro risco -, um homem que se "aventurou" no longínquo inospitaleiro - quando partiu sempre com grandes estruturas, com helicópteros e equipes. Wim Wenders e o filho do fotógrafo reproduzem, como no imaginário da criança que via seu pai partir para terras longínquas, a imagem mítica de um fotógrafo heroico e desbravador - mas que, na realidade, jamais soube questionar a sua posição de observador e se vê à parte do mundo de horrores que ele busca retratar.

As fotografias de Salgado, em sua estetização mortífera, permanecem o símbolo de um exotismo intocável - e tanto mais quanto seu discurso sobre as diferenças do sofrimento no terceiro mundo (o continente africano, por exemplo) e no primeiro mundo (a guerra da Iugoslávia, por exemplo) reforça a distância e o exotismo do terceiro mundo. Benjamin antecipou de forma surpreendente o poder de captura mágica do capitalismo em sua capacidade de tudo transformar em mercadoria enlatada - até mesmo o combate à miséria.

9 A crítica de Benjamin à forma-retrato não implica a impossibilidade de abandonar o homem como objeto da fotografia. O filósofo avança justamente como o cinema russo soube se valer do rosto e da fisionomia para melhor apreender um meio ou uma paisagem (Poudovkin, por exemplo). Ou ainda, Auguste Sander, um dos pais do documentário, partindo da "observação direta", reúne em A face do nosso tempo (1929) retratos de "tipos" de pessoas vindo de diferentes meios sociais. Benjamin reconhece aí uma forma de empirismo que precede a teorização e permite uma nova forma de observação do real. 
Informar o mundo de suas misérias não é suficiente: é preciso antes propiciar uma relação crítica às imagens. Benjamin percebe o perigo dessas imagensespelho, onde o sujeito sacia a sua culpa narcísica vendo reflexos de uma realidade longínqua. E essas realidades permanecerão imutáveis, intensificando dessa forma sua impotência niilista, enquanto o sujeito não puder interrogar suas causas, seus funcionamentos, suas conexões. A essas imagens seria preciso contrapor outras, imagens esburacadas que perfurem, desloquem e abalem o sujeito.

\section{III "Estrangeirizar"}

Para Benjamin, tanto o teatro épico de Brecht, através do distanciamento e da técnica de interrupção, quanto a fotografia de um Atget, por exemplo, propiciam uma atitude ativa e crítica porque interrompem a normalidade de situações que são tomadas como naturalmente dadas. A noção de Entfremdung tem um papel aqui fundamental. Resta entender como essa palavra, tão carregada e problematizada por Marx, pôde ser retomada e positivada por Benjamin. Se para o autor de $O$ Capital esse termo se refere à alienação produzida pela fantasmagoria capitalista, para Benjamin ela diz respeito justamente ao meio de se escapar à alienação - à incapacidade do sujeito de ver por ter se tornado tão habituado e adaptado ao seu meio.

Dois elementos permitem compreender a reutilização do termo por Benjamin. Em primeiro lugar, o filósofo põe a fotografia sob o signo da psicanálise freudiana como uma técnica capaz de nos ensinar sobre o inconsciente visual. A Entfremdung não pode ser compreendida senão se conectada a um outro termo, o de Unheimlich, a inquietante estranheza. Em Freud (1919), esse termo ambíguo concerne à consciência da radicalidade do estranho-estrangeiro que nos habita. O mais próximo, o íntimo, o lar (Heim) teria se tornado estrangeiro, inquietante, Unheimlich. Mas, para o psicanalista, o estrangeiro (der Fremder) não é propriamente Unheimlich. Nesse sentido, Freud (1936) vai chegar a outro termo, a Entfremdung, que é ligada ao esforço do sujeito em excluir algo de si mesmo. Benjamin retomando essas ideias faz da Entfremdung o resultado de uma operação ativa - tornar estranho, "estrangeirizar".

Em segundo lugar, é importante notar como toda uma outra tradição retoma a palavra Entfremdung em seu sentido negativo de alienação. Essa tradição, representada por um Heidegger, por exemplo, diz respeito à maneira como o sujeito se distanciou do Ser, vivendo agora na inautenticidade. Heidegger prefere antes a palavra Entfernung, o distanciamento ou afastamento necessário em relação às coisas, de modo que o sujeito possa reencontrar o que é próprio, 
originário, autêntico (cf. Heidegger, 1977, §23). Tanto Benjamin quanto Heidegger argumentam a favor de uma operação ativa de distanciamento, mas os termos são diferentes e reenviam a campos semânticos distintos. A escolha de Benjamin pela palavra Entfremdung é dessa forma também estratégica e concerne à necessidade de se opor semanticamente a uma rede de significantes que se conecta à ideia de autenticidade. Quem fala em autenticidade, fala também de inautenticidade e em seguida de degenerado - a entartete Kunst, cuja exposição foi realizada em 1937 em Munique e cujo termo Entartung (degeneração) é exatamente o mesmo evocado constantemente por Heidegger para descrever o sujeito e o "eu" moderno em suas aulas de 1940 sobre Nietzsche e o niilismo europeu.

Sabe-se que certas mudanças estruturais entre as versões de 1935 e a de 1939 de "A obra de arte na era de sua reprodutibilidade" são consequência das críticas feitas por Adorno. Mas podemos imaginar que a publicação em 1936 de $A$ origem da obra de arte, de Heidegger, também influenciou certas mudanças. Heidegger pensa a obra de arte nesse texto a partir de um ponto de vista mitologizante, abstrato, sem levar em conta as transformações técnicas. A "Pequena história da fotografia" é uma história materialista que leva em conta a técnica fotográfica em seus momentos históricos, assim como em seguida a necessidade de se repensar a própria arte em relação ao advento da fotografia; "A obra de arte", por sua vez, dá continuidade a esse projeto, pensando agora, sobretudo, o cinema e segundo a perspectiva de uma mudança estrutural entre a arte tradicional e a arte moderna. Heidegger, ao contrário, faz uma história do "espírito" da arte, na sua relação com a essência, com o ser e com a verdade. O primeiro pensa a "evolução" histórica da arte e analisa práticas artísticas; o segundo, seguindo os passos de Hegel (cf. o posfácio de $A$ origem da obra de arte), pensa o processo de decadência, para os modernos, da Arte e do fim de sua necessidade vital, analisando, pois, um conceito completamente abstrato de Arte - "A origem das obras de arte e dos artistas é a Arte" (Heidegger, 1936, p. 46).

É nesse sentido que podemos, por exemplo, compreender a mudança do terceiro capítulo da versão de 1935 do texto de Benjamin que se abre sobre a questão da unicidade da obra de arte, seu hic et nunc, que fundaria a sua "autenticidade" e a forma como toda a ideia de autenticidade é destruída pela reprodutibilidade técnica. A reprodutibilidade descaracteriza a importância do aqui e agora, visto que podemos hoje escutar um concerto em casa ou observar um quadro no catálogo. Ainda mais, a própria ideia de original perde seu sentido com a fotografia e o negativo, de forma que "a autoridade da coisa vacila" (Benjamin, GS1, p. 438). Na versão de 1939, essa parte do texto desaparece e o segundo capítulo recebe uma nota de pé de página que desloca inteiramente a 
questão: o conceito de "autenticidade" é uma categoria que interessa ao mercado da arte e em realidade não é senão com a reprodução técnica que ela se torna uma noção relevante. Esse pequeno deslocamento é interessante do ponto de vista materialista, pois se, para Heidegger, a obra de arte é definida a partir de uma irrupção no mundo da verdade do Ser e se essa abertura diz respeito à autenticidade e, portanto, à autoridade da obra, Benjamin faz do conceito de "autenticidade" não mais um valor em si, mas um valor puramente histórico e o que é passível de ser destruído na era da reprodutibilidade técnica é antes a aura das obras, substituindo a ocorrência única da obra pela série. ${ }^{10}$ Enfim, "com a secularização da arte, a autenticidade toma o lugar do valor de culto" (Benjamin, GS1, p. 481). Em outras palavras, a autenticidade não diz mais respeito à garantia da origem; ela diz respeito a uma categoria mercadológica e também ao culto e portanto a um valor autoritário.

O que está em jogo nesse debate é a oposição entre duas concepções de arte que são expostas ao longo dos diferentes textos de Benjamin desse período. Essas concepções são exclusivas e contraditórias. O fascismo trabalha precisamente sobre a renovação da personalidade artística (a personalidade criadora, o gênio) do culto, da aura, da obra completa orgânica clássica, da origem, da verdade, da contemplação. Todas essas noções, relativas à arte tradicional e cultual, são combatidas e relegadas por Benjamin ao passado. ${ }^{11}$ Seu esforço consiste em mostrar que na modernidade possuímos, enfim, os meios para emancipar a arte. A emancipação da arte não significa para o filósofo que ela passa a valer em si mesma, mas antes que não depende mais de formas já feitas, de conteúdos precisos nem tampouco do antigo modo cultual de se relacionar com ela. Tratase, sobretudo, de emancipar a arte de sua "existência parasitária no ritual" (Benjamin, GS1, p. 483). Lá onde a arte morre para Hegel - e para Heidegger -, para Benjamin ela se emancipa.

Emancipar a arte significa enfim pensá-la em termos de técnica coletiva, de emancipação coletiva das massas. $\mathrm{O}$ fascismo promove uma noção de arte a partir de conceitos e noções tradicionais que visam recriar uma hierarquização completa da sociedade, que visam dar autoridade a líderes espirituais. Tratase de uma estratégia cujo objetivo é bloquear formas de auto-organização da sociedade. E, nessa perspectiva, o artista - e de certa forma o intelectual - é um ser iluminado, o gênio, que permanece à parte, ao lado, em face das

10 Por outro lado, como aponta Benjamin, essa destruição positiva possui também um aspecto negativo, a saber, está intimamente ligada ao capitalismo, que faz do objeto um produto, uma mercadoria.

11 Por isso Benjamin critica com veemência e reconhece o teor reacionário da expectativa daqueles que aguardam o surgimento de um novo "Goethe" ou "Gottfried Keller" (Benjamin, GS2, p. 696). 
massas. A fim de se contrapor a esse modelo, Benjamin aposta, como vimos, na transformação do modo de produção. Tal transformação deveria se tornar a tarefa primordial dos artistas revolucionários.

$\mathrm{O}$ alvo de Benjamin nos textos desse período é tanto o fascismo - que reconstrói constantemente a diferença absoluta entre o artista e o espectador quanto o capitalismo ou a arte burguesa que não produz senão um espectador passivo. Os termos são próximos aos de um Pasolini (1965), que pensa seu "cinema de poesia" enquanto capaz de criar espectadores ativos face ao cinema hollywoodiano do espectador passivo. Por isso, interessa a Benjamin toda a arte capaz de ativar o observador. Com efeito, trata-se de obras que interrompam a associação "natural", que interrompam a imaginação. A faculdade da imaginação é em Benjamin uma faculdade passiva, dotada de uma dimensão perigosa segundo a qual associações inadequadas facilmente se propagam. O filósofo percebe que na imaginação reside a ameaça real capaz de produzir verdadeiros delírios coletivos.

Se a forma tradicional da arte é a contemplação, o recolhimento ou a imersão em si, cujo paradigma teológico é "a consciência de estar sozinho com deus" (Benjamin, GS1, p. 502), lá onde o sujeito tem a impressão de estar "livre" em suas associações, o paradigma artístico para Benjamin é antes o do choque capaz justamente de interromper tais associações. Benjamin pensa na "antipintura" dadaísta que é feita contra a contemplação. Poderíamos ainda pensar na roda de bicicleta de Duchamp (1913), cujo objetivo seria não girar em torno do objeto para contemplá-lo, mas antes a evocação do movimento do corpo, a relação entre o olhar e o corpo ativado pela roda.

É nesse "efeito do choque" (Benjamin, GS1, p. 503) que Benjamin reconhece uma das potências do cinema: por conta de seu encadeamento de imagens, não é possível para o espectador se fixar na imagem - a temporalidade da contemplação é assim impossibilitada. A prática de cinema sublinhada por Benjamin, o cinema revolucionário, não é aquela que captura o espectador deixando-lhe em posição de fruição, mas antes a que o abala e assim o ativa. É preciso ressaltar aqui que essa ativação pode ser também efetuada pelo riso. Esse tema, longamente desenvolvido, sobretudo, na versão de 1935 de $\mathrm{A}$ obra de arte (cf. capítulo 16) mostra a importância dada por Benjamin ao sentido corporal da ativação - bem antes da espiritual, se contrapondo assim mais uma vez à retórica fascista. ${ }^{12}$

12 Mas também à retórica de um Adorno que, em sua visão extremamente elitista, criticará profundamente essas páginas de A obra de arte. Sobre esse tema da ativação ou, mais precisamente, da "inervação", ver a primeira parte do artigo "Le moindre geste ou Infância em Cevennes por volta de 1960" (Miguel, 2014). 
A potência do cinema e da interrupção da imaginação se resume em uma frase do texto Scenes de la vie future (1930), de Georges Duhamel, citada por Benjamin no texto sobre $A$ obra de arte: "Eu não posso mais pensar o que quero pensar" (Benjamin, GS1, p. 503). Pensar o que se quer voluntariamente é saber o que se pensa, é permanecer no "bom senso e no senso comum" do já conhecido - ou seja, nas tautologias das palavras de ordem como souberam mostrar tão bem Deleuze e Guattari. ${ }^{13}$ Justamente Deleuze, em Diferença e repetição, faz um belo comentário da correspondência entre Artaud e Rivière mostrando que a "incapacidade" de pensar do escritor - Je n'arrive pas à penser, escrevia ele - diz respeito antes a uma força que perfura o senso comum, a associação passiva e imaginativa do senso comum - do pensar como. O mesmo Deleuze, em $A$ imagem-tempo, comentando a invenção documentária de um Perrault ou de um Rouch, sublinha essa forma de cinema em que se trata de se tornar outro - tanto o cineasta que filma quanto os "personagens" documentados. "A célebre fórmula - 'o que é fácil no documentário é que sabemos quem somos e quem filmamos' - deixa de valer. A forma de identidade $\mathrm{Eu}=\mathrm{Eu}$ (ou sua forma degenerada eles=eles) deixa de valer para as personagens e para o cineasta, tanto no real quanto na ficção. O que se insinua, em graus profundos, é antes o 'Eu é outro' de Rimbaud” (Deleuze, 2005, p. 185).

"Eu não posso mais pensar o que quero pensar." A potência da arte para Benjamin reside, portanto, em obras capazes de abalar e deslocar o sujeito - e sua vontade, seu lugar comum, sua representação. Trata-se de não deixá-lo mais se submeter à associação passiva, à contemplação, ao recolhimento e, portanto, à identificação. Tal é a política do olho pensada por Benjamin, cujo princípio é o estranhamento do outro em mim. Tal é o caminho para uma emancipação possível. Contra o subjetivismo e o individualismo da arte burguesa, contra o retorno à origem do corpo da massa única e indivisível do fascismo, a aposta benjaminiana foi a de uma abertura de si capaz de dar aos sujeitos o impulso de recriar uma nova coletividade.

\section{Conclusão}

A arte tem para Benjamin um papel fundamental: interromper o reconhecimento, a significação e a repetição, abrindo espaço ao estranho, ao imprevisível, ao singular. Não a reprodução, mas a transformação - que está

13 “Toda a teoria racionalista clássica, de um 'senso comum', de um bom senso universalmente compartilhado, fundado na informação e na comunicação, é uma maneira de encobrir ou de ocultar e de justificar previamente uma faculdade muito mais inquietante que é a das palavras de ordem" (Deleuze; Guattari, 1980, p. 108). 
no coração mesmo do humano e de suas capacidades expressivas, segundo esse postulado antropológico que é a base mesma da filosofia benjaminiana. Nesse sentido, a socialização dos meios de produção artística é necessária também para que alcancemos uma socialização dos meios de apropriação e de fabricação de nossos corpos. Para lutar contra a alienação estrutural identificada por Benjamin da Alemanha do entreguerras por meio do socialismo não haveria outra saída senão uma luta pela socialização e pela coletivização em todos os niveis. Por isso, a simples convicção político-ideológica do artista ou do intelectual não é suficiente. É preciso agir concretamente no sentido dessa coletivização. Essa aposta começa com a ideia de que se o espectador se tornasse capaz de buscar por seus próprios meios de se exprimir singularmente em vez de buscar a identificação com o corpo-modelo heroico e olímpico representado no cinema “exemplar" de uma Leni Riefenstahl ou com o corpo da estrela hollywoodiana, então ele estaria mais preparado para não se identificar imediatamente com a massa homogênea liderada por um guia.

Não se trata de modo algum de opor indivíduo singular e massa coletiva, mas antes de compreender ativamente qual corpo, qual atitude, se está adquirindo de forma mecânica, automática, irrefletida; ou ainda quem está impondo uma certa conduta, uma certa gestualidade coreografada e segundo quais formas, pois tais formatações do corpo e das atitudes não estariam senão limitando o indivíduo e tanto mais na medida em que ele nunca poderá reproduzir realmente um corpo que não é o seu, criando assim um ciclo de frustração sem fim.

A aposta de Benjamin é a de uma busca de autofabricação, de modo emancipado. Mas tal fabricação não é a de um indivíduo isolado. Ela só é possível a partir do seu contato com outros indivíduos: sem mediação e compartilhando os meios de produção. A oposição não é por consequência entre indivíduo e massa/ coletivo, mas entre mediação e ausência de mediação. Trata-se de mediação entre os indivíduos por uma figura superior, mas também por uma imagem normativa e ideológica do corpo único da massa. Poderiam os indivíduos se auto-organizarem para criar, sem a mediação dessa imagem, tomando em mãos os meios de produção a fim de que fabriquem eles mesmos suas imagens? Essa é a aposta de Benjamin.

Se a origem - origem da obra de arte, origem racial e do povo, origem do Estado e da verdade etc. - é o grande fantasma do fascismo, então todas as forças do "Movimento" são canalizadas para o retorno a essa origem e para a sua conservação - por isso trata-se de uma "revolução" conservadora, contra a decadência da história moderna e ocidental. A grande imagem dessa origem é o corpo indiviso da massa única e homogênea que se move naturalmente e sem orientação - pois o Führer não é senão um órgão que representa imediatamente o todo porque idêntico a ele. 
O fascismo se aproveita das técnicas modernas para precisamente criar o mito desse corpo único e indiviso enquanto imagem icônica a ser incorporada e reproduzida. A estratégia do fascismo é a estruturação de um mimetismo reduzido e silencioso, a partir do qual os indivíduos se imitam uns aos outros sem perceberem, levando a um automatismo delirante. $\mathrm{O}$ regime afetivo vivido (ódio, medo, tristeza e frustração) é propício e alimentado. As massas, esse "material" imprescindível para o sucesso do "Movimento", são como que coreografadas e estrategicamente conduzidas; as ações são homogeneizadas, automatizadas, normalizadas: colaboracionismo, denunciação, linchagem, assassinato são gestos tornados cotidianos, capturados em um automatismo absoluto. A dinâmica desse corpo das massas, no período vivido por Benjamin, explica bem o porquê da insistência tão grande do filósofo na necessidade vital de interromper o seu automatismo corporal. Com efeito, havia se tornado urgente tornar uma vez mais estrangeirizar essas situações agora tão familiares.

\section{Referências}

BARTHES, R. "La chambre claire: note sur la photographie". Paris: Gallimard, 1980. BENJAMIN, W. "Gesammelte Schriften" (GS). 14 tomos. Frankfurt: Surhkamp, 1974. . "Walter Benjamin Briefe I". Frankfurt: Surhkamp, 1978. "Écrits Français". Paris: Gallimard, 1993.

DELEUZE, G. "Différence et répétition". Paris: PUF, 1968.

"Imagem-tempo. Cinema 2". (1985). Tradução de E. A. Ribeiro. São Paulo: Brasiliense, 2005.

DELEUZE, G., GUATTARI, F. (1980). "Mille Plateaux”. Paris: Éditions de Minuit, 2006. FAYE, J. P. (1972). "Langages totalitaires: critique de la raison narrative, [critique de] l'économie [narrative]". Paris: Hermann, 1996.

FREUD, S. (1919). "Das Unheimliche". In: Kleine Schriften II. Capítulo 29. Projeto Gutenberg. Disponível em: http://gutenberg.spiegel.de/buch/kleine-schriften-ii-7122/1 (Acessado em 29 de agosto de 2017).

. (1936). "Brief an Romain Rolland (Eine Erinnerungsstörung auf der Akropolis)". In: Kleine Schriften II. Capítulo 17. Projeto Gutenberg. Disponível em: http://gutenberg. spiegel.de/buch/kleine-schriften-ii-7122/1 (Acessado em 29 de agosto de 2017).

GOEBBELS, J. “Kampf um Berlin”. München: Zentralverlag der NSDAP, Franz Eher Nachf, 1934.

HEIDEGGER, M. (1927). "Sein und Zeit”. In: Gesamtausgabe I. Abteilung: Veroffentliche Schriften 1914-1970. Volume 1. Frankfurt: Vittorio Klostermann, 1977.

. (1936). "Der Ursprung des Kunstwerkes". In: Gesamtausgabe I. Abteilung:

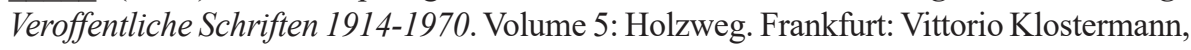
1977. 

1986.

. (1940). "Nietzsche: Der europäische Nihilismus". Frankfurt: Vittorio Klostermann,

LEROI-GOURHAN, A. "Le geste et la parole". 2 Vol. Paris: Albin Michel, 1964.

MAUSS, M. (1936). "Les techniques du corps". Journal de Psychologie, XXXII, Nr., 3-4, 15 mars/15 avril 1936. Disponível em: http://classiques.uqac.ca/classiques/mauss marcel/socio_et_anthropo/6_Techniques_corps/Techniques_corps.html (Acessado em 29 de agosto de 2017).

MIGUEL, M. "Le Moindre Geste ou Infância em Cevennes por volta de 1960". Revista Poiésis, Nr. 24, pp. 93-108, dez. 2014. Disponível em: http://www.poiesis.uff.br/p24/ pdf/p24-dossie-6-marlon-miguel.pdf (Acessado em 29 de agosto de 2017).

MIGUEL, M., OLIVEIRA, L. S., RIVERA, T. (ed.). "Revista Poiésis", Vol. 1, Nr. 24, 2014. Disponível em: http://www.poiesis.uff.br/p24/sumario24.html (Acessado em 29 de agosto de 2017).

NICHOLS, B. (ed.). "Movies and Methods". Vol. 1. Berkeley: University of California Press, 1976.

PASOLINI, P. P. (1965). “The Cinema of Poetry”. Ed. B. Nichols, 1976. pp. 542-558. RANCIÈRE, J. (1987). "Le maître ignorant: cinq leçons sur l'émancipation intellectuelle". Paris: Fayard, 2004.

. "O que me interessa é tentar pensar em formas de travessia, ao largo e em diagonal, em relação ao trajeto normal dos saberes sociais". Revista ao Largo, Nr. 4, 2017. [Online] Disponível em: https://www.maxwell.vrac.puc-rio.br/29631/29631.PD FXXvmi=4xxAzhOfRaenS01gQ1brIEB30v9TMi3RQBrqTgGMrVblVcCNdNgWsR 1snbmbtp312vMWNtJfqUBn8ebm2rkvjlZIwmU2NZnQubNjGxA7sbuCqG0t8k0rH0 bfm6hb5G2BRPUxnuGRHbu9SuD1QDtxDFO1M7cSNetG5pfsVW1E8QN1mq3d4w MIdBJ0JWSwcnehOuLKr7oBZcClEGzJdlrqxcrHalfmJuEz1pjsxJ4wWHSBnrkCON3 N1vubRLxChcbi (Acessado em 29 de agosto de 2017).

ROTHE, W. "Der Aktivismus 1915-1920”. München: DTV, 1969.

SLOTERDIJK, P. "O desprezo das massas: ensaio sobre lutas culturais na sociedade moderna”. Tradução de C. Cavalcanti. São Paulo: Estação Liberdade, 2002. 